\title{
Siewert Type I
}

National Cancer Institute

\section{Source}

National Cancer Institute. Siewert Type I. NCI Thesaurus. Code C154610.

An adenocarcinoma of the lower esophagus with the center located $1 \mathrm{~cm}$ to $5 \mathrm{~cm}$ above the esophagogastric junction. 